\title{
Linoleic and $\alpha$-linolenic acids differently modify the effects of elaidic acid on polyunsaturated fatty acid metabolism and some immune indices in rats
}

\author{
BY TAMIHO KOGA', MICHIKO NONAKA ${ }^{2}$, JONG YAN GU ${ }^{2}$ \\ AND MICHIHIRO SUGANO ${ }^{2}$
}

${ }^{1}$ Department of Food and Nutrition, Nakamura Gauen College, Jyonan-ku, Fukuoka 814-01, Japan
${ }^{2}$ Laboratory of Food Science, Kyushu University School of Agriculture, Higashi-ku, Fukuoka 812-81,
Japan

(Received 2 November 1995 - Revised 12 July 1996 - Accepted 14 August 1996)

To explore whether the metabolic responses to trans, compared with cis, fatty acids depend on the source of dietary polyunsaturated fatty acids (PUFA), male Sprague-Dawley rats, 5 weeks old, were fed on diets containing $30 \mathrm{~g}$ oleic (cis) or elaidic (trans) acids/kg in combination with either $70 \mathrm{~g}$ perilla oil ( $\alpha$-linolenic acid) or safflowerseed oil (linoleic acid)/kg for 3 weeks in separate experiments. The dietary fats were adjusted to have the same level of total PUFA. The dietary manipulation did not influence the growth indices, but spleen weight was greater when the dietary PUFA source was perilla oil. The incorporation of trans fatty acid into liver phosphatidylcholine, phosphatidylethanolamine, phosphatidylinositol and phosphatidylserine and adipose tissue lipids, particularly phospholipids, was significantly higher when rats were fed on safflowerseed oil compared with perilla oil. However, only limited differences were observed in the efiects of $c i s$ and trans fatty acids on the proportions of PUFA in liver phospholipids. Splenic production of prostaglandin $E_{2}$ was reduced by trans fatty acid when safflowerseed oil was the PUFA source, but no trans effect was observed on leukotriene $C_{4}$ production. Dietary PUFA significantly influenced the concentration of plasma immunoglobulins (Ig) but the effect of geometry was only seen in IgG which was increased by trans acid. Dietary trans fatty acid increased the $\mathrm{CD4}^{+}: \mathrm{CDB}^{+} \mathrm{T}$-lymphocyte ratio in the spleen, reflecting a decreasing trend of the proportion of $\mathrm{CDB}^{+}$, when combined with perilla oil. These observations indicate that the type of PUFA simultaneously ingested specifically influences the effect that trans acid exerts on PUFA metabolism, eicosanoid production and some immune indices.

Elaidic acid: Oleic acid: $\alpha$-Linolenic acid: Linoleic acid: Eicosanoids

The undesirable effects of trans octadecenoic acids on the concentration of plasma cholesterol and the profile of plasma lipoproteins have been reported for human subjects (Mensink \& Katan, 1990; Mensink et al. 1992; Nestel et al. 1992; Troisi et al. 1992; Zock \& Katan, 1992; Wood et al. 1993; Abbey \& Nestel, 1994; Almendingen et al. 1995; KrisEtherton, 1995), and the effects are apparently dose-dependent (Mensink \& Katan, 1990; Zock \& Katan, 1992). In addition, certain epidemiological studies have indicated a possible link between trans fatty acids and the development of coronary heart disease (Willet et al. 1993; Mann, 1994; Ascherio \& Willet, 1995). In well-controlled animal studies, however, trans octadecenoic acids are not hypercholesterolaemic (Zevenbergen \& Haddeman, 1989; Borlak \& Welch, 1994). In fact, trans monoenes, compared with their cis counterparts, do not change plasma cholesterol concentrations in rats (Sugano et al. 1989) 
or the LDL receptor activity in hamsters (Woollet et al. 1994), although these findings are still controversial (Hayashi et al. 1993). Since human diets are much more complex in their compositions than the purified diets used in animal studies, these discrepancies might, at least in part, be attributed to the influence of dietary components consumed simultaneously.

One such possibility is the nature of the polyunsaturated fatty acids (PUFA) consumed. PUFA of different families, $n-3$ and $n-6$, appear to influence plasma lipid levels differently (Harris 1989; Schmidt et al. 1993). Hence, in the present study we investigated how dietary $n-3$ and $n-6$ PUFA modify the effect that trans fatty acids exert on the various variables of lipid metabolism. Since trans fatty acids interfere with the metabolism of linoleic acid to arachidonic acid and, hence, the eicosanoid production from arachidonic acid (Kinsella et al. 1981; Sugano et al. 1989), we measured the production of prostaglandin $\mathrm{E}_{2}$ and leukotriene $\mathrm{C}_{4}$ which are both typical chemical mediators. Since dietary PUFA significantly influence immune functions (Yaqoob \& Calder, 1993), the effects of these dietary manipulations on the serum levels of immunoglobulins and splenic T-lymphocyte subsets were also studied. Thus, male rats were given elaidic acid (trans) or oleic acid (cis) in combination with vegetable oils rich in either $\alpha$-linolenic or linoleic acids.

\section{MATERIALS AND METHODS}

\section{Animals and diets}

Two experiments were carried out in succession using male 4-week-old Sprague-Dawley rats (Seiwa Experimental Animals, Fukuoka, Japan). The animals were caged individually in a room with controlled temperature $\left(20-22^{\circ}\right)$ and lighting (06.00-18.00 hours), and freely accessible AIN-type purified diets (American Institute of Nutrition, 1977) for 3 weeks after 1 week of acclimation. The diet contained the following ingredients $(\mathrm{g} / \mathrm{kg})$ : casein 200 ; fat 100 , mineral mixture 35 , vitamin mixture 10 , choline bitartrate 2 , cellulose 50 , maize starch 150 , and sucrose 453 . The dietary fat was composed of octadecenoic acids, either oleic (cis) or elaidic (trans) acid (Wako Pure Chemicals, Osaka, Japan) and edible-grade vegetable oils in the proportions $3: 7(\mathrm{w} / \mathrm{w})$. The elaidic acid corresponded to approximately $6 \%$ energy. The vegetable oils used were perilla oil (from the seed of Perilla frutesens; Ohta Oil Co., Okazaki, Japan) in one experiment and a mixture of safflowerseed oil (Linol Oil Co., Nagoya, Japan) and palm oil (Fuji Oil Co., Osaka, Japan) $(8.7: 1 \cdot 0, \mathrm{w} / \mathrm{w})$ in the other experiment. Using this combination, the content of total PUFA, linoleic and $\alpha$-linolenic acids, was comparable between the two experiments, and in each experiment the difference in the geometry (cis or trans) of octadecenoic acid was the sole

Table 1. Fatty acid compositions ( $\mathrm{g} / 100 \mathrm{~g}$ total fatty acids) of dietary fats*

\begin{tabular}{lcccccc}
\hline \hline & \multicolumn{5}{c}{ Fatty acid } \\
\cline { 2 - 7 } Dietary fat & $16: 0$ & $18: 0$ & trans-18:1 & cis-18:1 & $18: 2 n-6$ & $18: 3 n-3$ \\
\hline Perilla oil diet & & & & & \\
$\quad$ cis & 4.4 & 1.3 & - & 46.5 & 9.0 & 38.7 \\
$\quad \begin{array}{l}\text { trans } \\
\text { Saffiowerseed oil diet }\end{array}$ & 4.4 & 1.4 & 32.0 & 13.7 & 9.0 & 39.6 \\
$\quad$ cis & 7.1 & 1.6 & - & 42.3 & 48.0 & - \\
$\quad$ trans & 7.1 & 1.6 & 30.0 & 12.3 & 47.9 & - \\
\hline
\end{tabular}

* Three parts of oleic or elaidic acid were mixed with seven parts of either perilla oil or a mixture of safflowerseed oil and palm oil $(8.7: 1, w / w)$, respectively. 
variable (Table 1). Body weight and food intake were recorded every other day. Rats were killed by withdrawing blood from the abdominal aorta under diethyl ether anaesthesia. Liver, spleen and abdominal adipose tissue were excised immediately. The experiments were performed under the Guidelines for Animal Experiments approved by Nakamura Gakuen University.

\section{Analytical procedures}

Liver and serum lipids were analysed for cholesterol, triacylglycerol and phospholipid as described elsewhere (Sugano et al. 1984). Liver phospholipids were separated into phosphatidylcholine, phosphatidylethanolamine, phosphatidylinositol, phosphatidylserine and cardiolipin by TLC, and their fatty acid compositions were analysed as methyl esters by GLC (Koga et al. 1994). The adipose tissue lipids were also extracted and their fatty acid compositions analysed. A portion of spleen was homogenized in phosphate-buffered

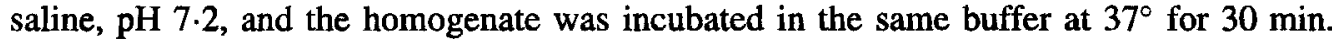
Leukotriene $\mathrm{C}_{4}$ was extracted from the medium and measured by radioimmunoassay using a commercial kit (NEK-030, New England Nuclear, Boston, MA, USA) under the linear relationship with respect to the homogenate volume and incubation time (Gu et al. 1994). Splenic prostaglandin $\mathrm{E}_{2}$ production was similarly measured (NEK 020, New England Nuclear) (Koga et al. 1994). Serum immunoglobulin (Ig) levels were measured by the sandwich ELISA as reported previously (Gu et al. 1994). In brief, mouse anti-rat IgA, rabbit anti-rat IgG $\left(\mathrm{Fab}^{\prime}\right)_{2}$, goat anti-rat IgE and goat anti-rat IgM (Zymed Lab, San Francisco, CA, USA) were used to fix respective immunoglobulins. After blocking the bound IgA, IgG and IgM were measured by reacting with their respective peroxidase (POD)-conjugated anti-rat immunoglobulins (Zymed Lab). For measurement of bound IgE POD-conjugated avidin (Betyl, Montgomery, TX, USA) was used. Spleen lymphocytes were separated by applying Lympholyte-Rat (Cedarlane, Hornby, Canada) and CD4 and CD8 positive T-cells were counted by flow cytometry (Epics Plofile II, Coulter Electronics Ltd, Luton, Beds.) (Gu et al. 1994).

\section{Statistical analysis}

After confirming the similarity of the variances ( $F$ values) of all the data, the results were analysed by $2 \times 2$ ANOVA (Gomez \& Gomez, 1984) followed by Duncan's new multiple range test (Duncan, 1955) to evaluate the statistical difference among the groups.

\section{RESULTS}

\section{Growth indices and tissue weights}

There were no significant differences in food intake and weight gain between cis and trans fat groups irrespective of the source of dietary PUFA (results not shown). The weights of liver and spleen were also comparable between the cis and trans fatty acid groups, but the latter was heavier after feeding perilla oil than after feeding safflowerseed oil ( 0.71 (SE 0.02 ) and 0.70 (SE 0.03) $\mathrm{g}$ for the cis and trans fatty acid groups on perilla oil diets, and 0.59 (SE 0.04) and 0.59 (SE 0.03) $\mathrm{g}$ for the corresponding groups on safflowerseed oil diets respectively, $P<0.05$ ). 


\section{Concentrations of serum and liver lipids}

Table 2 summarizes the concentrations of serum and liver lipids. Statistically significant differences in serum lipids were observed for the concentrations of triacylglycerol and phospholipid. The concentration of serum triacylglycerol tended to be lower in rats fed on perilla oil than in those fed on safflowerseed oil, and it was lowest in the perilla oil-trans fatty acid combination. When trans fatty acid was fed, the serum phospholipid level was significantly lower in the perilla oil group than in the safflowerseed group, and there was a significant interaction with dietary PUFA. Although the source of dietary monounsaturated fatty acids did not influence the concentrations of serum cholesterol, they tended to be lower when rats were fed on perilla oil and there was a significant interaction in the concentration of serum cholesterol. In liver lipids, the only marked difference was observed for the concentration of phospholipid, which was significantly higher in rats fed on safflowerseed oil than in those fed on perilla oil. The concentration of liver phospholipid was significantly higher in the trans group than in the cis group when perilla oil was fed. These differences were not observed when rats were fed on safflowerseed oil. There was a PUFA-dependent difference in the concentration of liver phospholipid.

\section{Fatty acid compositions of liver phospholipids}

The fatty acid compositions of the liver phospholipid classes are summarized in Tables 3 and 4. Elaidic acid was incorporated at similar levels into phosphatidylcholine, phosphatidylethanolamine and phosphatidylinositol, while the extent of incorporation was lower in phosphatidylserine for each PUFA source. Apparently no trans fatty acid was incorporated into cardiolipin in either of the PUFA groups. However, the incorporation of trans fatty acid was always significantly higher in rats fed on safflowerseed oil than in those fed on perilla oil. In all phospholipid classes the compositions of PUFA were not substantially modified by the geometrical difference in the dietary octadecenoic acids,

Table 2. Effects of elaidic acid on concentrations of serum and liver lipids in rats fed on diets containing perilla oil or safflowerseed oil

(Mean values with their standard errors for eight rats)

\begin{tabular}{|c|c|c|c|c|c|c|c|c|c|c|c|c|}
\hline \multirow[b]{3}{*}{ Group } & \multicolumn{6}{|c|}{ Serum lipids (mmol/l) } & \multicolumn{6}{|c|}{ Liver lipids $(\mu \mathrm{mol} / \mathrm{g})$} \\
\hline & \multicolumn{2}{|c|}{ Cholesterol } & \multicolumn{2}{|c|}{$\begin{array}{c}\text { Triacylgly- } \\
\text { cerol }\end{array}$} & \multicolumn{2}{|c|}{ Phospholipid } & \multicolumn{2}{|c|}{ Cholesterol } & \multicolumn{2}{|c|}{$\begin{array}{l}\text { Triacylgly- } \\
\text { cerol }\end{array}$} & \multicolumn{2}{|c|}{ Phospholipic } \\
\hline & Mean & SE & Mean & SE & Mean & SE & Mean & SE & Mean & SE & Mean & SE \\
\hline \multicolumn{13}{|l|}{ Perilla oil diet } \\
\hline cis & 1.66 & 0.05 & $1.77^{\mathrm{ab}}$ & 0.22 & $2 \cdot 29^{\mathrm{ab}}$ & 0.05 & $10 \cdot 2^{\mathrm{ab}}$ & 0.6 & 39.8 & 2.7 & $36 \cdot 0^{\mathrm{a}}$ & 0.8 \\
\hline trans & 1.59 & 0.12 & $1.29^{\mathrm{a}}$ & 0.11 & $2 \cdot 0^{\mathrm{a}}$ & $0 \cdot 11$ & $9 \cdot 3^{\mathrm{a}}$ & $1 \cdot 0$ & 32.4 & 1.4 & $43 \cdot 0^{b}$ & 1.2 \\
\hline \multicolumn{13}{|l|}{ Safflowerseed oil diet } \\
\hline cis & 1.89 & $0 \cdot 13$ & $2 \cdot 12^{\mathrm{b}}$ & 0.21 & $2 \cdot 23^{\mathrm{ab}}$ & 0.11 & $11 \cdot 8^{\mathrm{b}}$ & 0.4 & $37 \cdot 5$ & $3 \cdot 1$ & $59.9^{c}$ & 1.5 \\
\hline trans & 1.82 & 0.10 & $2 \cdot 01^{b}$ & 0.24 & $2 \cdot 44^{\mathrm{b}}$ & 0.15 & $10 \cdot 6^{a b}$ & 0.7 & 37.5 & 5.0 & $56 \cdot 6^{\mathrm{c}}$ & $3 \cdot 1$ \\
\hline Pooled SE & \multicolumn{2}{|c|}{0.12} & \multicolumn{2}{|c|}{0.25} & \multicolumn{2}{|c|}{0.18} & \multicolumn{2}{|c|}{0.8} & \multicolumn{2}{|c|}{5.2} & \multicolumn{2}{|c|}{4.7} \\
\hline \multicolumn{13}{|l|}{ ANOVA $F$ value } \\
\hline PUFA & \multirow{2}{*}{\multicolumn{2}{|c|}{$\begin{array}{c}P<0.05 \\
\text { NS }\end{array}$}} & \multirow{2}{*}{\multicolumn{2}{|c|}{$\begin{array}{c}P<0.05 \\
\text { NS }\end{array}$}} & \multicolumn{2}{|c|}{ NS } & \multicolumn{2}{|c|}{ NS } & \multicolumn{2}{|c|}{ NS } & \multirow{2}{*}{\multicolumn{2}{|c|}{$\begin{array}{c}P<0.01 \\
\text { NS }\end{array}$}} \\
\hline cis-trans & & & & & \multirow{2}{*}{\multicolumn{2}{|c|}{$P<0.05$}} & \multirow{2}{*}{\multicolumn{2}{|c|}{$\begin{array}{l}\text { NS } \\
\text { NS }\end{array}$}} & \multirow{2}{*}{\multicolumn{2}{|c|}{$\begin{array}{l}\text { NS } \\
\text { NS }\end{array}$}} & & \\
\hline Interaction & \multicolumn{2}{|c|}{ NS } & \multicolumn{2}{|c|}{ NS } & & & & & & & \multicolumn{2}{|c|}{$P<0.01$} \\
\hline
\end{tabular}

a,b.c Mean values within a column not sharing a common superscript letter were significantly different, $P<0.05$ (df 28 ).

* For details of diets see Table 1 and p. 646. 


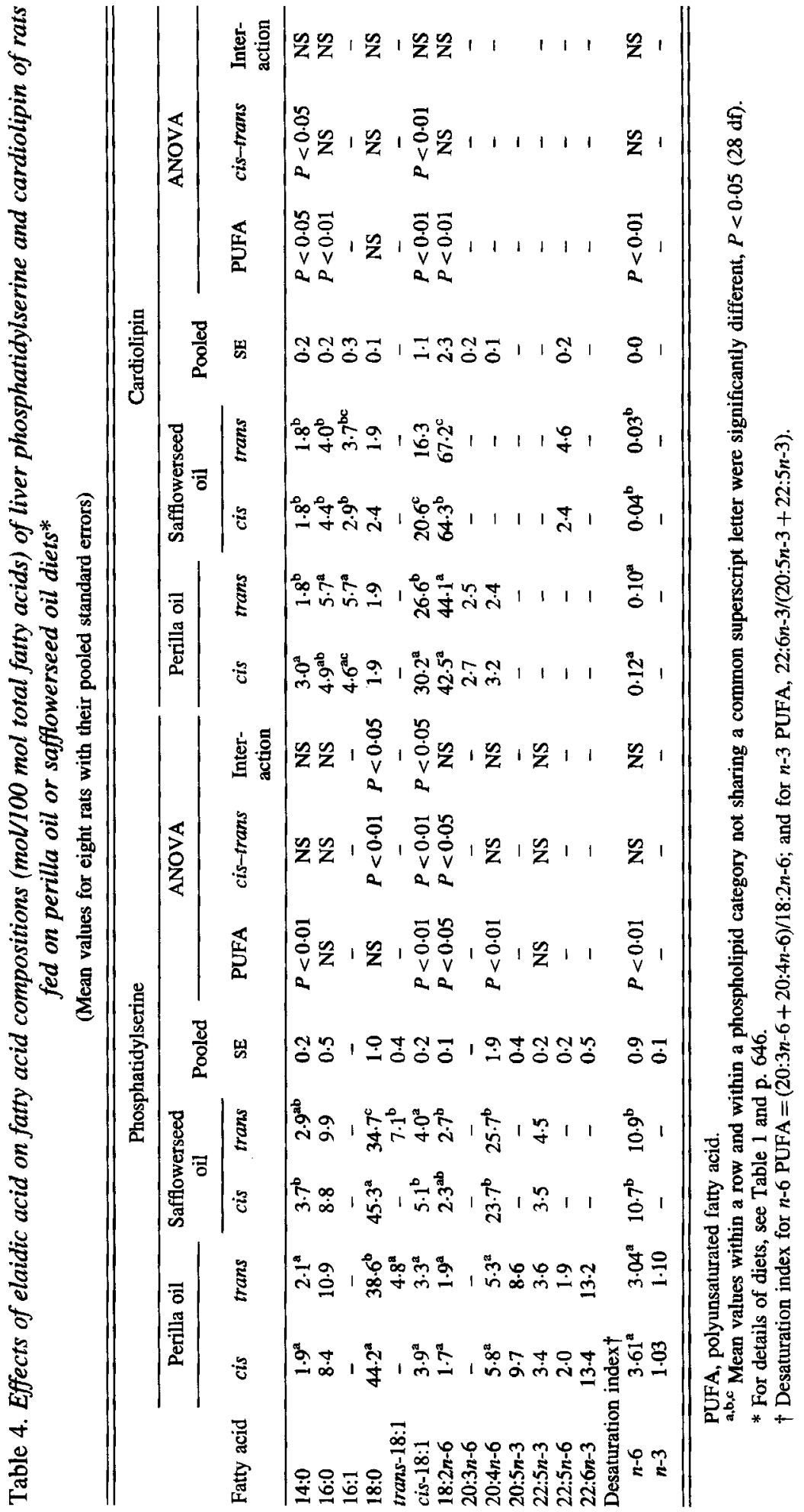


although they reflected the type of dietary PUFA. Thus, the proportion of arachidonic acid was significantly higher, while that of docosahexaenoic acid $(22: 6 n-3)$ was significantly lower in rats fed on safflowerseed oil compared with those fed on perilla oil. Consequently, the desaturation indices for $n-3$ and $n-6$ PUFA $(22: 6 n-3 /(20: 5 n-3+22: 5 n-3)$ and $(20: 3 n-$ $6+20: 4 n-6) / 18: 2 n-6$ respectively) were not markedly influenced by the difference in the geometry of dietary monounsaturated fatty acids.

ANOVA showed a significant effect of the geometrical difference on the proportion of linoleic acid in phospholipids except for phosphatidylinositol and cardiolipin. The desaturation index for linoleic acid was also dependent on PUFA and/or the geometry in phospholipids except for phosphatidylinositol.

\section{Fatty aid compositions of adipose tissue lipids}

As shown in Table 5, the fatty acid composition of adipose tissue total lipids reflected that of the dietary fats. Slightly but significantly more elaidic acid was detected in rats fed on safflowerseed oil than in those fed on perilla oil. Although the type of dietary PUFA was reflected in the PUFA composition of adipose tissue lipids, the concentration of PUFA in adipose tissue was significantly lower when rats were given trans fatty acid compared with cis fatty acid. The decrease in the proportion of oleic acid by dietary elaidic acid was not totally compensated for by the incorporation of trans monoene fatty acid. Instead, the proportion of palmitoleic acid significantly increased on feeding trans fatty acid irrespective of the dietary PUFA.

\section{Splenic production of leukotriene $C_{4}$ and prostaglandin $E_{2}$}

Dietary trans fatty acid did not influence the splenic production of leukotriene $\mathrm{C}_{4}$ in rats fed on either the $n-3$ or the $n$-6 PUFA diet (Table 6). However, perilla oil markedly reduced the production compared with safflowerseed oil, and there was a significant interaction of dietary PUFA on this variable. The production of prostaglandin $E_{2}$ was measured only in the experiment with safflowerseed oil, and it was significantly reduced by elaidic acid.

Table 5. Effects of elaidic acid on fatty acid compositions (mol/100 mol total fatty acids) of adipose tissue of rats fed on perilla oil or safflowerseed oil diets*

(Mean values with their standard errors for eight rats)

\begin{tabular}{|c|c|c|c|c|c|c|c|c|c|c|c|c|}
\hline \multirow[b]{3}{*}{ Fatty acid } & \multicolumn{4}{|c|}{ Perilla oil } & \multicolumn{4}{|c|}{ Safflowerseed oil } & \multirow{3}{*}{$\begin{array}{c}\text { Pooled } \\
\text { SE }\end{array}$} & \multirow{2}{*}{\multicolumn{3}{|c|}{ ANOVA $F$ value }} \\
\hline & \multicolumn{2}{|c|}{ cis } & \multicolumn{2}{|c|}{ trans } & \multicolumn{2}{|c|}{ cis } & \multicolumn{2}{|c|}{ trans } & & & & \\
\hline & Mean & SE & Mean & SE & Mean & $\mathrm{SE}$ & Mean & SE & & PUFA & cis-trans & Interaction \\
\hline $14: 0$ & $1.8^{\mathrm{a}}$ & 0.1 & $1.9^{\mathrm{a}}$ & 0.0 & $1 \cdot 2^{\bar{b}}$ & 0.0 & $1 \cdot 3^{\bar{b}}$ & $\overline{0.0}$ & 0.1 & $P<0.01$ & NS & NS \\
\hline $16: 0$ & $21 \cdot 0^{\mathrm{a}}$ & 0.7 & $23 \cdot 5^{\mathrm{b}}$ & $0 \cdot 3$ & $20 \cdot 9^{a}$ & 0.5 & $21 \cdot 6^{\mathrm{a}}$ & 0.8 & 0.4 & NS & $P<0.05$ & NS \\
\hline $16: 1$ & $5 \cdot 2^{a}$ & 0.2 & $7 \cdot 3^{\mathrm{b}}$ & 0.2 & $4 \cdot 1^{\mathrm{c}}$ & 0.3 & $5 \cdot 9^{\mathrm{a}}$ & 0.3 & 0.2 & $P<0.01$ & $P<0.01$ & NS \\
\hline $18: 0$ & $2 \cdot 1^{\mathrm{a}}$ & 0.0 & $1.8^{b}$ & 0.1 & $2 \cdot 3^{\mathrm{a}}$ & 0.1 & $1.6^{b}$ & 0.0 & 0.1 & NS & $P<0.01$ & $P<0.01$ \\
\hline trans-18:1 & - & & $11 \cdot 6^{\mathrm{a}}$ & 0.2 & - & & $13 \cdot 4^{b}$ & 0.2 & 0.3 & - & - & - \\
\hline cis-18:1 & $41 \cdot 2^{\mathrm{a}}$ & 0.4 & $24 \cdot 3^{b}$ & 0.5 & $40 \cdot 1^{\mathrm{c}}$ & 0.2 & $20 \cdot 5^{\mathrm{d}}$ & 0.2 & 1.7 & $P<0.01$ & $P<0.01$ & $P<0.01$ \\
\hline $18: 2 n-6$ & $8-2^{\mathrm{a}}$ & 0.4 & $7.7^{\mathrm{a}}$ & 0.3 & $30 \cdot 0^{b}$ & 0.7 & $34.1^{c}$ & 0.8 & $2 \cdot 2$ & $P<0.01$ & $P<0.01$ & $P<0.01$ \\
\hline $18: 3 n-3$ & $20 \cdot 0^{\mathrm{a}}$ & 0.5 & $22 \cdot 0^{\mathrm{b}}$ & 0.5 & $0 \cdot 3^{\mathrm{c}}$ & 0.0 & $0.5^{\mathrm{c}}$ & 0.1 & 2.0 & $P<0.01$ & $P<0.01$ & $P<0.05$ \\
\hline
\end{tabular}

PUFA, polyunsaturated fatty acid.

a.b.c Mean values within a row not sharing a common superscript letter were significantly different, $P<0.05$ (28 df).

* For details of diets, see Table 1 and p. 646. 
Table 6. Effects of elaidic acid on splenic production of leukotriene $C_{4}$ and prostaglandin $E_{2}$ in rats fed on perilla oil or safflowerseed oil diets*

(Mean values with their standard errors for eight rats)

\begin{tabular}{|c|c|c|c|c|c|c|c|c|c|c|c|c|}
\hline & \multicolumn{4}{|c|}{ Perilla oil diet } & \multicolumn{4}{|c|}{ Safflowerseed oil diet } & \multirow{3}{*}{$\begin{array}{c}\text { Pooled } \\
\text { SE }\end{array}$} & \multirow{2}{*}{\multicolumn{3}{|c|}{ ANOVA $F$ value }} \\
\hline & \multicolumn{2}{|c|}{ cis } & \multicolumn{2}{|c|}{ trans } & \multicolumn{2}{|c|}{ cis } & \multicolumn{2}{|c|}{ trans } & & & & \\
\hline & Mean & SE & Mean & SE & Mean & SE & Mean & SE & & PUFA & trans & action \\
\hline Leukotriene $\mathrm{C}_{4}$ (ng/g spleen) & 49.7 & $2 \cdot 3$ & 52.4 & 10.5 & 432 & 63 & 326 & 25 & $33 \cdot 2$ & $P<0.01$ & NS & NS \\
\hline Prostaglandin $E_{2}$ (ng/g spleen) & ND & & ND & & $3 \cdot 54^{\mathrm{a}}$ & 0.94 & $1 \cdot 31^{\mathrm{b}}$ & 0.51 & 0.64 & - & - & - \\
\hline
\end{tabular}

PUFA, polyunsaturated fatty acid; ND, not determined.

${ }^{\mathrm{a}, \mathrm{b}}$ Mean values within a row with unlike superscript letters were significantly different, $P<0.05$ (28 df).

*For details of diets, see Table 1 and p. 646.

Table 7. Effects of elaidic acid on splenic T-lymphocyte subsets in rats fed on diets containing perilla oil or safflowerseed oil*

(Mean values with their standard errors for eight rats)

\begin{tabular}{|c|c|c|c|c|c|c|}
\hline \multirow[b]{3}{*}{ Group } & \multicolumn{6}{|c|}{ T-lymphocyte } \\
\hline & \multicolumn{2}{|c|}{$\mathrm{CD}^{+}(\%)$} & \multicolumn{2}{|c|}{$\mathrm{CD8}^{+}(\%)$} & \multicolumn{2}{|c|}{$\mathrm{CD}^{+}: \mathrm{CD}^{+}$} \\
\hline & Mean & SE & Mean & SE & Mean & SE \\
\hline \multicolumn{7}{|l|}{ Perilla oil diet } \\
\hline cis & 25.2 & $1 \cdot 1$ & $21.9^{\mathrm{a}}$ & $1 \cdot 3$ & $1 \cdot 17^{\mathrm{a}}$ & 0.06 \\
\hline trans & 25.4 & 1.0 & $17 \cdot 0^{\mathrm{a}}$ & 0.7 & $1 \cdot 50^{\mathrm{b}}$ & 0.04 \\
\hline \multicolumn{7}{|l|}{$\begin{array}{l}\text { Safflowerseed } \\
\text { oil diet }\end{array}$} \\
\hline cis & $25 \cdot 1$ & $1 \cdot 3$ & $14.5^{\mathrm{b}}$ & 0.8 & $1.75^{\mathrm{c}}$ & 0.09 \\
\hline trans & $26 \cdot 0$ & $1 \cdot 1$ & $15 \cdot 6^{\mathrm{b}}$ & 0.6 & $1.57^{b c}$ & 0.05 \\
\hline $\begin{array}{l}\text { Pooled SE } \\
\text { ANOVA F value }\end{array}$ & \multicolumn{2}{|c|}{0.53} & \multicolumn{2}{|c|}{0.67} & \multicolumn{2}{|c|}{0.05} \\
\hline PUFA & \multicolumn{2}{|c|}{ NS } & \multicolumn{2}{|c|}{$P<0.01$} & \multicolumn{2}{|c|}{$P<0.01$} \\
\hline cis-trans & \multicolumn{2}{|c|}{ NS } & \multicolumn{2}{|c|}{$P<0.05$} & \multirow{2}{*}{\multicolumn{2}{|c|}{ NS }} \\
\hline Interaction & \multicolumn{2}{|c|}{ NS } & \multicolumn{2}{|c|}{$P<0.01$} & & \\
\hline
\end{tabular}

PUFA, polyunsaturated fatty acid.

a,b,c Mean values within a column not sharing a common superscript letter were significantly different, $P<0.05$ (28 df).

*For details of diets, see Table 1 and p. 646.

\section{Splenic T-lymphocyte subsets}

The results are shown in Table 7. Dietary manipulations did not influence the proportion of splenic $\mathrm{CD}^{+}$T-lymphocytes, but that of $\mathrm{CD8}^{+}$cells decreased when rats were fed on safflowerseed oil rather than perilla oil. Dietary trans fatty acid did not influence these variables. However, the $\mathrm{CD}^{+}: \mathrm{CD}^{+}$ratio was higher in the elaidic acid group than in the oleic acid group when perilla oil was fed, but not when safflowerseed oil was fed. ANOVA showed PUFA- and geometry-dependent differences in the proportion of CD8 ${ }^{+}$.

\section{Plasma concentrations of immunoglobulins}

Table 8 shows the concentrations of plasma immunoglobulins. When the PUFA source was perilla oil, the concentration of $\operatorname{IgA}$ was significantly lower, while those of IgG and IgM 
Table 8. Effects of elaidic acid on plasma immunoglobulin levels in rats fed on diets containing perilla oil or safflowerseed oil*

(Mean values with their standard errors for eight rats)

\begin{tabular}{|c|c|c|c|c|c|c|c|c|}
\hline \multirow[b]{3}{*}{ Group } & \multicolumn{8}{|c|}{ Immunoglobulin } \\
\hline & \multicolumn{2}{|c|}{$\underset{(\mu \mathrm{g} / \mathrm{ml})}{\operatorname{IgA}}$} & \multicolumn{2}{|c|}{$\underset{(\mathrm{ng} / \mathrm{ml})}{\mathrm{IgE}}$} & \multicolumn{2}{|c|}{$\underset{(\mathrm{mg} / \mathrm{ml})}{\mathrm{IgG}}$} & \multicolumn{2}{|c|}{$\underset{(\mathrm{ng} / \mathrm{ml})}{\operatorname{IgM}}$} \\
\hline & Mean & SE & Mean & SE & Mean & $\mathrm{SE}$ & Mean & SE \\
\hline \multicolumn{9}{|l|}{ Perilla oil diet } \\
\hline cis & $1.87^{\mathrm{a}}$ & 0.14 & $17 \cdot 8^{\mathrm{a}}$ & $1 \cdot 1$ & $5 \cdot 23^{\mathrm{a}}$ & 0.56 & $93 \cdot 1^{\mathrm{a}}$ & $8 \cdot 5$ \\
\hline trans & $1.47^{\mathrm{b}}$ & 0.28 & $20 \cdot 7^{\mathrm{a}}$ & 1.5 & $6.90^{b}$ & 0.58 & $159^{\mathrm{b}}$ & 11 \\
\hline \multicolumn{9}{|c|}{ Safflowerseed oil diet } \\
\hline cis & $34 \cdot 2^{\mathrm{c}}$ & 2.6 & $4 \cdot 54^{b}$ & 0.78 & $1 \cdot 19^{\mathrm{c}}$ & 0.21 & $160^{b}$ & 23 \\
\hline trans & $33 \cdot 4^{\mathrm{c}}$ & 4.8 & $4.84^{b}$ & $0-84$ & $1.40^{\circ}$ & 1.10 & $188^{b}$ & 18 \\
\hline Pooled SE & \multicolumn{2}{|c|}{0.48} & \multicolumn{2}{|c|}{1.43} & \multicolumn{2}{|c|}{0.48} & \multicolumn{2}{|c|}{$3 \cdot 2$} \\
\hline \multicolumn{9}{|c|}{ ANOVA $F$ value } \\
\hline PUFA & \multirow{2}{*}{\multicolumn{2}{|c|}{$\begin{array}{c}P<0.01 \\
\text { NS }\end{array}$}} & \multirow{2}{*}{\multicolumn{2}{|c|}{$P<0.01$}} & \multirow{2}{*}{\multicolumn{2}{|c|}{$\begin{array}{l}P<0.01 \\
P<0.05\end{array}$}} & \multirow{2}{*}{\multicolumn{2}{|c|}{$\begin{array}{c}P<0.01 \\
\text { NS }\end{array}$}} \\
\hline cis-trans & & & & & & & & \\
\hline Interaction & \multicolumn{2}{|c|}{ NS } & \multicolumn{2}{|c|}{ NS } & \multicolumn{2}{|c|}{ NS } & \multicolumn{2}{|c|}{ NS } \\
\hline
\end{tabular}

PUFA, polyunsaturated fatty acid.

${ }_{a, b, c}$ Mean values within a column not sharing a common superscript letter were significantly different, $P<0-05$ (28 df).

* For details of diets, see Table 1 and p. 646.

were significantly higher on feeding trans acid than on feeding the cis counterpart. No such differences were observed when the PUFA source was safflowerseed oil. The concentration of IgA was significantly higher, while those of $\mathrm{IgE}$ and $\mathrm{IgG}$ were significantly lower, in the safflowerseed oil group than in the perilla oil group. ANOVA showed significant PUFAdependent differences in the levels of all immunoglobulins, while a geometry-dependent difference was only evident for IgG.

\section{DISCUSSION}

There were detectable differences in the metabolic implications of elaidic acid with respect to the type of PUFA simultaneously ingested. Although the protocol of the present study (i.e. that two experiments were done separately) should be taken into consideration, the $F$ values for various variables including growth indices and tissue weights were not statistically different. Thus, the comparisons were made on two experiments by two-way ANOVA followed by Duncan's multiple range test (Duncan, 1955).

The incorporation of trans fatty acid into liver phospholipids was approximately 1.5 times higher when linoleic acid was the source of PUFA than when $\alpha$-linolenic acid was the major source of PUFA. This observation may simply indicate an alleviation by $n-3$ PUFA of the possible undesirable effect of trans fatty acid.

A study by Bernard et al. (1987) indicated that elaidic acid was absorbed to a lesser extent than oleic acid, and that the absorption rate appeared to be influenced by the type of fatty acid simultaneously infused through a duodenal cannula. In the present experiments, the incorporation of elaidic acid into adipose tissue lipids was slightly but significantly higher in rats fed on safflowerseed oil than in those fed on perilla oil. Since the fatty acid composition of adipose tissues routinely reflects that of dietary fats (Tjonneland et al. 1993), the different interference of individual PUFA with elaidic acid absorption seems 
unlikely in the present study. It is also plausible that $\alpha$-linolenic acid stimulates the metabolism of trans fatty acid. Elaidic acid caused a small but significant increase in the proportion of $\alpha$-linolenic and linoleic acids in adipose tissue when the dietary fat supplied large amounts of these PUFA. Thus, elaidic acid may, alternatively, interfere with the utilization of PUFA, since in adipose tissue PUFA, particularly $\alpha$-linolenic acid, appear to be mobilized most rapidly of all the fatty acids (Cunnane et al. 1991).

In contrast, the compositions of PUFA in liver phospholipids were not essentially modified by the difference in the geometry of octadecenoic acids, and they apparently reflected those of dietary PUFA. It has been reported that trans fatty acids interfere with the desaturation of linoleic acid to arachidonic acid, and hence eicosanoid production (Kinsella et al. 1981; Sugano et al. 1989), but this effect disappears when the supply of essential linoleic acid is satisfactory (Zevenbergen \& Haddeman, 1989; Koga et al. 1994). In the present study, the perilla oil diet supplied approximately $2 \%$ energy as linoleic acid, which corresponds to the minimal requirement of this essential fatty acid for rats. Although a similar response pattern of the PUFA composition of spleen phospholipids is deduced between the cis and trans groups (Koga et al. 1994), this dietary level of linoleic acid may be border line in its ability to compensate for the effect of elaidic acid, since splenic production of prostaglandin $E_{2}$ decreased significantly in rats fed on trans fat in combination with safflowerseed oil. The observation that splenic leukotriene $\mathrm{C}_{4}$ production was not influenced by the dietary fat sources indicates a possible difference in the sensitivity of the enzymic systems producing individual eicosanoids. A marked reduction of splenic leukotriene $\mathrm{C}_{4}$ production after feeding perilla oil can be attributed to the incorporation of $n$-3 PUFA in phospholipids (Yaqoob \& Calder, 1993). It is known that PUFA of the $n-3$ family interfere with the production of eicosanoids from arachidonic acid (Kinsella et al. 1990).

A PUFA-dependent difference in the concentrations of liver lipids was also observed, although the effects were not so marked. Previously, we reported that trans monoene fatty acids in partially hydrogenated vegetable oil were not hypercholesterolaemic in the rat model, compared with the cis counterparts and they simultaneously reduced the liver triacylglycerol level (Sugano et al. 1989). The hypocholesterolaemic effect was not reproduced in the present study with cholesterol-free diets, even when combined with $\alpha$ linolenic acid (Drevon, 1992).

The different effects of $n-3$ and $n-6$ PUFA on the metabolic effects of cis and trans octadecenoic acid were also observed in some immune variables. Elaidic acid in combination with perilla oil increased the $\mathrm{CD}^{+}$helper T-cells : $\mathrm{CD} 8^{+}$suppressor T-cells ratio. However, this was not the case with safflowerseed oil. Huang \& Fritsche (1992) observed an increase in spleen weight and immune cell yield in mice fed on diets high in high-oleic safflowerseed oil or menhaden oil compared with those fed on a high-linoleic safflowerseed oil diet, probably in response to the change in the fatty acid composition of phospholipids. It was suggested that the changes in the fatty acid compositions of membrane phospholipids of the immune cells might, directly or indirectly, influence their proliferation and/or migration (Novo et al. 1987). Although the current observation is difficult to interpret, it is at least likely that the immunological effect of elaidic acid may be modified by the source of dietary PUFA. Fly \& Johnston (1990) showed that serum from previously immunized rats fed on $n-3$ PUFA-containing oils (Canola (rapeseed) and soyabean oils) contained significantly more antibody to bovine serum albumin than that from rats fed on maize oil, suggesting a difference in IgM production. Thus, trans fatty acid when fed with $n-3$ PUFA, compared with $n-6$ PUFA, may enhance the immune defence function. The observation that the concentrations of plasma IgG and IgM were 
significantly higher in the elaidic acid group than in the oleic acid group in rats fed on perilla oil was not explained by the change in T-lymphocyte subsets in the spleen (Katz, 1980). Although the physiological significance of the current observation on the immune variables is not apparent at present, the results at least indicate diverse interactions of elaidic acid with different PUFA.

In conclusion, the present study indicated that the metabolic effects of elaidic acid are readily modified by the type of dietary PUFA, either $n-3$ or $n-6$, consumed simultaneously. $\alpha$-Linolenic acid appeared to have more marked effects than linoleic acid in this respect. Thus, the present results emphasize the critical importance of the type of PUFA in evaluating the metabolic effects of trans fatty acid. However, due to the design of the present study it is difficult to draw definite conclusions about whether the observed differences are solely attributable to PUFA.

The skilful technical assistance of Mr Y. Itoh and B. D. Lim is appreciated.

\section{REFERENCES}

Abbey, M. \& Nestel, P. J. (1994). Plasma cholesteryl ester transfer protein activity is increased when transelaidic acid is substituted for cis-oleic acid in the diet. Atherosclerosis 106, 99-107.

Almendingen, K., Jordal, O., Kierulf, P., Sandstad, B. \& Pedersen, J. I. (1995). Effect of partially hydrogenated fish oil, partially hydrogenated soybean oil, and butter on serum lipoproteins and Lp[a] in men. Journal of Lipid Research 36, 1370-1384.

American Institute of Nutrition (1977). Report of the American Institute of Nutrition ad hoc Committee on standards for nutritional studies. Journal of Nutrition 107, 1340-1348.

Ascherio, A. \& Willet, W. C. (1995). Metabolic and atherogenic effects of trans fatty acids. Journal of Internal Medicine 238, 93-96.

Bernard, A., Echinard, B. \& Carlier, H. (1987). Differential intestinal absorption of two fatty acid isomers: elaidic and oleic acids. American Journal of Physiology 253, G751-G759.

Borlak, J. T. \& Welch, V. A. (1994). Health implications of fatty acids. Arzneimittel Forschung 44, $976-981$.

Cunnane, C. S., Chen, Z.-Y., Yang, J., Liede, A. C., Hamadeh, M. \& Crawford, M. A. (1991). $\alpha$-Linolenic acid in humans: direct functional role or dietary precursor? Nutrition 7, 437-439.

Drevon, C. A. (1992). Marine oils and their effects. Nutrition Reviews 50, 38-45.

Duncan, D. B. (1995). Multiple range and multiple F tests. Biometrics 1, 1-42.

Fly, A. D. \& Johnston, P. V. (1990). Tissue fatty acid composition, prostaglandin synthesis, and antibody production in rats fed corn, soybean, or low erucic acid rapeseed oil (Canola oil). Nutrition Research 10, 1299-1310.

Gomez, K. A. \& Gomez, A. A. (1984). Statistical Procedures for Agricultural Research, 2nd ed., pp. 91-97. New York: John Wiley \& Sons.

Gu, J.-Y., Nonaka, M., Yamada, K., Yoshimura, K., Takasugi, M., Ito, Y. \& Sugano, M. (1994), Effects of sesamin and $\alpha$-tocopherol on the production of chemical mediators and immunoglobulins in Brown-Norway rats. Bioscience Biotechnology Biochemistry 58, 1855-1858.

Harris, W. S. (1989). Fish oil and plasma lipid and lipoprotein metabolism in humans: a critical review. Journal of Lipid Research 30, 785-807.

Hayashi, K., Hirata, Y. Kurushima, H., Saeki, M., Amioka, H., Nomura, S., Kuga, Y., Ohkura, Y., Ohtani, H. \& Kajiyama, G. (1993). Effect of dietary hydrogenated corn oil trans-octadecenoate rich oil on plasma and hepatic cholesterol metabolism in the hamster. Atherosclerosis 99, 97-106.

Huang, S.-C. \& Fritsche, K. L. (1992). Alteration in mouse splenic phospholipid fatty acid composition and lymphoid cell populations by dietary fat. Lipids $27,25-32$.

Katz, D. H. (1980). Recent studies on the regulation of IgE antibody synthesis in experimental animals and man. Immunology 41, 1-24.

Kinsella, J. E., Braughton, K. S. \& Whalen, J. W. (1990). Dietary unsaturated fatty acids: interactions and possible needs in relation to eicosanoid synthesis. Journal of Nutritional Biochemistry 1, 123-141.

Kinsella, J. E., Bruckner, G., Mai, J. \& Shimp, I. (1981). Metabolism of trans fatty acids with emphasis on the effect of trans trans-octadecaenoate on lipid composition, essential fatty acid and prostaglandins: an overview. American Journal of Clinical Nutrition 34, 2307-2318.

Koga, T., Yamato, T., Gu, J.Y., Nonaka, M., Yamada, K. \& Sugano, M. (1994). Diversity in the incorporation into tissue phospholipids and effects on eicosanoid production of trans-monoene fatty acid in rats fed with different dietary proteins. Bioscience Biotechnology Biochemistry 58, 384-387. 
KrisEtherton, P. M. (1995). Trans fatty acids and coronary heart disease risk. American Journal of Clinical Nutrition 62, S651-S656.

Mann, G. V. (1994). Metabolic consequence of dietary trans fatty acids. Lancet 343, 1268-1271.

Mensink, R. P. \& Katan, M. B. (1990). Effect of dietary trans fatty acids on high-density and low-density lipoprotein cholesterol levels in healthy subjects. New England Journal of Medicine 323, 439-445.

Mensink, R. P., Zock, P. L., Katan, M. B. \& Hornstra, G. (1992). Effect of dietary cis and trans fatty acids on serum lipoprotein(a) levels in humans. Journal of Lipid Research 33, 1493-1501.

Nestel, P. J., Noakes, M., Belling, B., McArthur, R., Clifton, P. M. \& Abbey, M. (1992). Plasma lipoprotein lipid and $L_{\mathrm{p}}(\mathrm{a})$ changes with substitution of elaidic acid for oleic acid in the diet. Joumal of Lipid Research 33, 1029-1036.

Novo, C., Fonseca, E. \& Frietas, A. A. (1987). Altered fatty acid membrane composition modifies lymphocyte localization in vivo. Cellular Immunology 106, 387-396.

Schmidt, E. B., Kristensen, S. D., De Caterina, R. \& Illingworth, D. R. (1993). The effects of $n-3$ fatty acids on plasma lipids and lipoproteins and other cardiovascular risk factors in patients with hyperlipidemia. Atherosclerosis 103, 107-121.

Sugano, M., Ryu, K. \& Ide, T. (1984). Cholesterol dynamics in rats fed cis-and trans-octadecenoate in the form of triglyceride. Journal of Lipid Research 25, 474-485.

Sugano, M., Watanabe, M., Yoshida, K., Miyamoto, M. \& Kritchevsky, D. (1989). Influence of dietary cis and trans-fats on DMH-induced colon tumors, steroid excretion, and eicosanoid production in rats prone to colon cancer. Nutrition and Cancer 12, 177-187.

Tjonneland, A., Overvad, K., Thorling, E. \& Ewertz, M. (1993). Adipose tissue fatty acids as biomarkers of dietary exposure in Danish men and women. American Joumal of Clinical Nutrition 57, 629-633.

Troisi, R., Willet, W. C. \& Weiss, S. T. (1992). Trans-fatty acid intake in relation to serum lipid concentrations in adult men. American Journal of Clinical Nutrition 56, 1019-1024.

Willet, W. C., Stampfer, M. J., Manson, J. E., Colditz, G. A., Speizer, F. E., Rosner, B. A., Sampson, L. A. \& Hennekens, C. H. (1993). Intake of trans fatty acids and risk of coronary heart disease among women. Lancet 341, 581-585.

Woollet, L. A., Daumerie, M. \& Dietschy, J. M. (1994). Trans-9-octadecenoic acid is biologically neutral and does not regulate the low density lipoprotein receptor as the cis isomer does in the hamster. Journal of Lipid Research 35, 1661-1673.

Wood, R., Kubena, K., O'Brien, B., Tseng, S. \& Martin, G. (1993). Effect of butter, mono- and polyunsaturated fatty acid-enriched butter, trans fatty acid margarine, and zero trans fatty acid margarine on serum lipids and lipoproteins in healthy men. Journal of Lipid Research 34, 1-11.

Yaqoob, P. \& Calder, P. C. (1993). The effects of fatty acids on lymphocyte functions. International Journal of Biochemistry 25, 1705-1714.

Zevenbergen, J. L. \& Haddeman, E. (1989). Lack of effects of trans fatty acids on eicosanoid biosynthesis with adequate intake of linoleic acid. Lipids 24, 555-563.

Zock, P. L. \& Katan, M. B. (1992). Hydrogenation alternatives: effects of trans fatty acids and stearic acid versus linoleic acid on serum lipids and lipoproteins in humans. Journal of Lipid Research 33, 399-410. 